\title{
PENURUNAN NYERI PADA IBU POST SECTIO CAESARIA PASCA INTERVENSI BIOLOGIC NURTURING BABY LED FEEDING
}

\author{
Susilo Rini ${ }^{1}$, Indri Heri Susanti ${ }^{2}$ \\ ${ }^{1}$ Prodi Kebidanan D3, STIKES Harapan Bangsa Purwokerto, Jawa Tengah \\ ${ }^{2}$ Prodi Keperawatan S1, STIKES Harapan Bangsa Purwokerto, Jawa Tengah \\ Email : susilorini385@yahoo.com
}

\begin{abstract}
ABSTRAK
Latar Belakang: Tindakan sectio caesarea (SC) menyebabkan nyeri yang menimbulkan berbagai masalah, salah satunya masalah laktasi. Sebanyak $68 \%$ ibu post sectio caesarea mengalami kesulitan dengan perawatan bayi, bergerak naik turun dari tempat tidur dan mengatur posisi yang nyaman selama menyusui akibat adanya nyeri. Akibat rasa nyeri tersebut menyebabkan pasien menunda pemberian ASI sejak awal pada bayinya. Posisi biologic nurturing baby led feeding merupakan salah satu posisi menyusui yang direkomendasikan bagi ibu nifas post SC karena lebih rileks. Selama ini penanganan ibu nifas dengan nyeri masing dengan pemberian analgetik peroral, sedangkan posisi menyusui biologic nurturing baby led feeding belum diterapkan.

Tujuan: Penelitian ini untuk menganalisis adanya penurunan nyeri pada ibu post sectio caesaria pasca intervensi biologic nurturing baby led feeding

Metode: Penelitian ini merupakan penelitian Quasi-eksperiment, dengan rancangan one group pretest-postest design. Penelitian dilakukan di RSUD Goeteng Taruna Dibrata Purbalingga. Populasi penelitian adalah seluruh ibu yang melahirkan secara SC, sampel yang digunakan sebanyak 41 responden yang diambil secara purposive sampling. Instrument untuk menilai nyeri menggunakan Numeric Rating Scale (NRS). Data dianalilis dengan menggunakan uji Wilcoxon

Hasil: Hasil penelitian menunjukan sebanyak 28 dari 41 responden $(68,3 \%)$ mengalami penurunan skala nyeri pasca intervensi biologic nurturing baby led feeding. Hasil analysis menunjukkan terdapat penurunan nyeri yang bermakna pada ibu post SC sebelum dan sesudah intervensi biologic nurturing baby led feeding $(p<0,01)$

Kesimpulan: Intervensi biologic nurturing baby led feeding dapat menurunkan nyeri pada ibu post sectio caesarea

Kata Kunci: Biologic Nurturing Baby Led Feeding; Nyeri; Sectio Caesaria

PENDAHULUAN

Masa nifas merupakan masa kritis baik bagi ibu maupun banyinya. Badan Kesehatan Dunia (WHO) menyatakan bahwa persalinan dengan bedah caesar adalah sekitar 10-15\% dari semua proses persalinan di negara berkembang. Bahkan, prosentase melahirkan sectio caesarea di rumah sakit swasta pada tahun 2004 rata-rata $20 \%$ dan persalinan normal $80 \%$. Sementara, menurut laporan kedokteran terbaru di tahun 2005 naik lagi menjadi 26,3\% dan 27,5\% di tahun 2006 (Kemenkes RI, 2013).

Tindakan operasi sectio caesarea

menyebabkan nyeri dan mengakibatkan terjadinya perubahan kontinuitas jaringan karena adanya pembedahan. Nyeri tersebut akan menimbulkan berbagai masalah, salah satunya masalah laktasi. Menurut Julianti, 2014 bahwa 68\% ibu post sectio caesarea mengalami kesulitan dengan perawatan bayi, bergerak naik turun dari tempat tidur dan mengatur posisi yang nyaman selama menyusui akibat adanya nyeri. Rasa nyeri tersebut akan menyebabkan pasien menunda pemberian ASI sejak awal pada bayinya (Aminah, 2011).

Penanganan yang sering digunakan
\end{abstract}


S Rini, I H Susanti | Penurunan Nyeri Pada lbu Post Sectio Caesaria Pasca Intervensi Biologic Nurturing Baby Led Feeding

untuk menurunkan nyeri post sectio caesarea biasanya menggunakan analgesic. Namun demikian pemberian farmakologi tidak bertujuan untuk meningkatkan kemampuan klien sendiri untuk mengontrol nyerinya. Sehingga dibutuhkan kombinasi farmakologi untuk mengontrol nyeri dengan non farmakologi agar sensasi nyeri dapat berkurang serta masa pemulihan tidak memanjang. Metode non farmakologi tersebut diperlukan untuk mempersingkat episode nyeri yang berlangsung hanya beberapa detik atau menit (Yuliatun, 2008).

Salah satu terapi non farmakologi untuk mengurangi nyeri post SC adalah menyusui dengan Posisi biologic nurturing baby led feeding. Posisi ini direkomendasikan bagi ibu nifas post SC karena lebih dirasakan rileks sehingga menyebabkan nyeri luka jahitan lebih minimal (Cholson, 2008).

Studi pendahuluan pada tanggal 2 Mei 2016 di RSUD Goeteng Taroenaibrata Purbalingga diketahui jumlah angka kejadian persalinan dengan sectio caesarea pada tahun 2015 sebanyak 420 dari 910 persalinan atau $46,15 \%$ diantaranya persalinan dengan metode sectio caesarea. Jumlah ini lebih banyak dibandingkan pada tahun 2014 yaitu 364 dari 890 persalinan atau 40,89\% dari seluruh kejadian persalinan. Sedangkan kasus laserasi perineum pada tahun 2015 sebanyak 340 dari 490 persalinan pervaginam atau $69,38 \%$. Luka persalinan tersebut menyebabkan nyeri pada ibu yang menyulitkan pemberian ASI Ekslusif dan memperlambat involusi uteri. Informasi dari dokter dan bidan, ibu nifas dengan nyeri post partum, penanganannya adalah dengan pemberian analgetik peroral dan untuk posisi menyusui biologic nurturing baby led feeding belum diterapkan. Sehingga peneliti tertarik untuk meneliti penurunan nyeri ibu post sectio caesaria pasca intervensi biologic nurturing baby led feeding di RSUD Goeteng Taruna Dibrata Purbalingga.

\section{METODE}

Desain penelitian ini adalah Quasi-eksperiment, dengan rancangan One Group Pretest-Postest design. Penelitian dilakukan di RSUD Goeteng Taroenadibrata Purbalingga. Populasi dalam penelitian ini adalah seluruh ibu yang melahirkan secara SC di RSUD Goeteng Taroenadibrata Purbalingga, sampel yang digunakan sebanyak 41 responden yang diambil secara purposive sampling, yang memenuhi kriteria inklusi (Hidayat, 2007).

Instrument untuk menilai nyeri ibu nifas menggunakan Numeric Rating Scale (NRS). Data nyeri diambil sebelum dan setalah dilakukan intervensi biologic nurturing baby led feeding. Data dalam penelitian ini tidak berdistribusi normal, sehingga analisis data yang digunakan ada dengan uji Wilcoxon (Hidayat, 2007). Apabila p-value < (a) 0,05 maka dinyatakan ada penurunan nyeri ibu post sectio caesaria pasca intervensi biologic nurturing baby led feeding

\section{HASIL}

Hasil penelitian menunjukkan mayoritas responden berusia reproduksi tidak beresiko (20-35 tahun) yaitu 32 orang $(78,1 \%)$ dan sebagian besar memiliki riwayat paritas tidak beresiko yakni paritas 2 dan $3(51,2 \%)$. Mayoritas responden mengalami penurunan 
skala nyeri lebih rendah daripada sebelum intervensi yaitu sebanyak 28 responden $(68,3 \%)$ dan yang skala nyerinya tetap sebanyak 13 responden (31.7\%). (Tabel 1).

Hasil uji Wilcoxon perbandingan skala nyeri ibu post Sectio Caecaria (SC) sebelum dan sesudah intervensi biologic nurturing baby led feeding, menunjukkan nilai $\mathrm{p}(0,001)$ lebih kecil dari 0,05 ( $p<\alpha$ 0,05) maka secara statistic terdapat perbedaan skala nyeri ibu post SC yang bermakna antara sebelum dan sesudah intervensi posisi menyusui biologic nurturing baby led feeding. Selisih mean rank lebih dari 10 menunjukkan, baik secara klinis maupun statistic terdapat perbedaan skala nyeri yang bermakna antara sebelum dan sesudah intervensi posisi menyusui biologic nurturing baby led feeding. (Tabel 2).

\section{PEMBAHASAN}

Hasil penelitian menemukan mayoritas responden mengalami penurunan skala nyeri lebih rendah daripada sebelum intervensi yaitu sebanyak $68.3 \%$. Hal ini dapat dikaitkan dengan jumlah mayoritas responden yang berada pada usia reproduksi sehat (usia 20-30 tahun) yang secara psikologis merupakan usia matang untuk mengendalikan emosi, termasuk respon menghadapi nyeri. Semakin matang usia seseorang maka semakin mampu mentoleransi rasa nyeri.

Jumlah mayoritas responden yang berada pada paritas 2 dan 3 yaitu sebanyak $51.2 \%$, juga dapat mempengaruhi penurunan skala nyeri karena sebagian besar responden telah memiliki pengalaman menghadapi nyeri pasca persalinan. Pengalaman ini dapat mengubah sensasi pasien terhadap nyeri.
Pengalaman persalinan terdahulu terkait dengan nyeri saat maupun setelah bersalin dengan atau tanpa secsio caecaria dapat membantu ibu mengelola manajemen nyeri dengan lebih siap. Hal ini sejalan dengan pendapat Nursalam (2015) bahwa faktor lain penyebab nyeri adalah persepsi dan toleransi individu terhadap nyeri, ambang nyeri, lingkungan, usia, pengalaman lampau, kebudayaan, kepercayaan, dan stress. Selama faktor ini masih kuat pengaruhnya bagi individu maka terapi farmakologi, sehingga diperlukan terapi non farmakologi untuk meningkatkan kemampuan individu dalam melakukan manajemen nyeri pasca bersalin (Lisa, dkk, 2017).

Perbedaan nyeri yang dirasakan responden didukung oleh Telfer dalam Fraser dan Cooper (2009) yang menyatakan nyeri merupakan fenomena multifaktor yang subjektif, personal dan kompleks yang dipengaruhi oleh 85 ontro-faktor psikologis, biologis, faktor budaya dan ekonomi. Perbedaan ini menunjukan bahwa intervensi biologic nurturing baby led feeding mampu mengalihkan toleransi nyeri dan ambang batas nyeri saat dan setelah ibu menjalani aktifitas menyusui dan kontak langsung dengan bayi, dengan menyusui ibu mau beradaptasi serta berespons terhadap nyeri dengan lebih baik, sehingga ibu lebih toleran terhadap rasa nyeri yang dialaminya.

Hasil uji Wilcoxon menunjukan perbandingan skala nyeri ibu post SC sebelum dan sesudah intervensi biologic nurturing baby led feeding dengan nilai $\mathrm{p}$ $(0,001)$ lebih kecil dari 0,05 $(p<\alpha 0,05)$ maka secara statistic terdapat perbedaan skala nyeri yang bermakna pada 
S Rini, I H Susanti | Penurunan Nyeri Pada lbu Post Sectio Caesaria Pasca Intervensi Biologic Nurturing Baby Led Feeding

Tabel 1. Karakteristik Responden $(n=41)$

\begin{tabular}{lcc}
\hline Karakteristik & Frekuensi & Persentase \\
\hline Kelompok Usia & & \\
$\quad$ Beresiko $(<20$ dan $>35$ tahun $)$ & 9 & $22.0 \%$ \\
$\quad$ Tidak beresiko (20-35 tahun) & 32 & $78.1 \%$ \\
Paritas & 20 & $48.8 \%$ \\
$\quad$ Beresiko $(\leq 1$ dan $\geq 4)$ & 21 & $51.2 \%$ \\
$\quad$ Tidak Beresiko $(2-3)$ & & $68.3 \%$ \\
Penurunan Skala Nyeri & 28 & $31.7 \%$ \\
$\quad$ Turun & 13 & \\
$\quad$ Tetap &
\end{tabular}

Tabel 2. Hasil Uji Perbedaan Penurunan Skala Nyeri Sebelum dan Setelah Intervensi Biologic Nurturing Baby Led Feeding $(\mathrm{n}=41)$

\begin{tabular}{ccccccc}
\hline Variabel & Kelompok & Mean & Mean dif & $\begin{array}{c}\text { Median } \\
(\text { Min-Max) }\end{array}$ & $\begin{array}{c}\text { Mean } \\
\text { Rank }\end{array}$ & p-value \\
\hline Skala Nyeri & Sebelum Intervensi & 4.76 & 1.42 & $5(1-10)$ & 14.50 & 0.001 \\
& Setelah Intervensi & 3.34 & & $3(0-8)$ & & \\
\hline Wilcoxon test & & & & & &
\end{tabular}

ibu post SC antara sebelum dan sesudah intervensi posisi menyusui biologic nurturing baby led feeding. Selisih mean rank lebih dari 10 maka baik secara klinis maupun statistic terdapat perbedaan skala nyeri yang bermakna antara sebelum dan sesudah intervensi posisi menyusui biologic nurturing baby led feeding.

Penurunan nyeri yang bermakna pada ibu post SC sebelum dan sesudah intervensi ini dipengaruhi oleh banyak faktor baik farmakologi maupun non farmakologi. Intervensi posisi menyusui biologic nurturing baby led feeding masuk dalam terapi nyeri nonfarmakologis, yaitu tanpa menggunakan obat-obatan, tetapi dengan memberikan teknik untuk mengurangi rasa nyeri yakni terapi distraksi yang memfokuskan perhatian pasien pada sesuatu selain nyeri, misalnya dengan menyusui (Watiyah, 2013). Hal ini mengacu pada teori gate control yang menyatakan bahwa impuls-impuls nyeri yang akan melewati gerbang (ujung-ujung saraf sensorik) dapat diatur atau dihambat oleh mekanisme pertahanan di sepanjang sistem saraf pusat. Impuls nyeri dihantarkan ketika gerbang dalam posisi terbuka dan akan dihentikan ketika gerbang ditutup (Potter and Perry, 2010). Posisi menyusui biologic nurturing baby led feeding dapat dijadikan penghambat (menutup) agar impuls saraf tidak dapat berjalan bebas sehingga tidak dapat mentransmisikan impuls atau pesan sensori ke korteks sensorik. Upaya menutup pertahanan tersebut merupakan dasar teori menghilangkan nyeri (Raymond, et all, 2009).

Proses persalinan menyebabkan kelelahan, bahkan trouma pada ibu, yang berdampak pada timbulnya rasa nyeri pasca bersalin, seperti disampaikan Kartikawati (2011) bahwa seseorang akan merasakan peningkatan sensasi nyeri saat tubuh mengalami kelelahan. Pada posisi biologic nurturing baby led feeding, ibu nifas menyusui dengan posisi rebahan sambil bersandar, dengan sudut kemiringan antara $15^{\circ}-64^{\circ}$ kemudian bayi diletakkan di atas dada, dan dibiarkan melekat dengan sendirinya. Pada cara ini, ibu tidak banyak mengintervensi posisi bayi, kedua tangan ibu bebas, 
memegang bayi sekedar untuk menjaganya agar tidak terguling, sehingga membuat ibu lebih nyaman, lebih tenang, dan lebih rileks, meminimalisir ketegangan di kepala, leher, pundak dan punggung. Ibu juga tidak perlu terlalu berkonsentrasi untuk memikirkan posisi dan pelekatan yang benar (Rini dan Dewi, 2016).

Hal ini sangat mendukung proses lepasnya hormon oksitosin sehingga mampu menghambat transmisi impuls atau pesan sensori ke korteks sensorik yang berdampak pada menurunnya skala nyeri pada ibu post SC. Hal ini sejalan dengan hasil penelitian Colson, dkk ( 2012) yang mengatakan bahwa posisi laid-back/semi-reclining atau rebahan dirasakan lebih nyaman oleh para ibu yang baru saja melahirkan, nyeri pada luka jahitan baik luka episiotomi ataupun luka operasi dirasakan lebih minimal dibandingkan duduk tegak, sehingga secara tidak langsung mendukung ibu untuk bertahan lebih lama dalam menyusui.

Penurunan nyeri pada ibu post SC pasca menyusui dengan biologic nurturing baby led feeding juga berkaitan dengan kontak kulit antara ibu dan bayinya yang disebut dengan terapi stimulasi kutaneus. Salah satu pemikiran tentang cara kerja khusus stimulasi kutaneus adalah menyebabkan pelepasan endorfin sehingga memblog transmisi stimulasi nyeri. Teori gate kontrol mengatakan bahwa stimulasi kutaneus mengaktifkan transmisi serabut saraf sensori A-Beta yang lebih besar dan lebih cepat. Proses ini menurunkan transmisi nyeri melalui serabut delta-A berdiameter kecil. Gerbang sinaps menutup transmisi impuls nyeri. Keuntungan stimulasi kutaneus adalah tindakan ini dapat dilakkan dirumah, sehingga memungkinkan klien dan keluarga melakukan upaya kontrol gejala nyeri dan penanganannya. Penggunaan yang benar dapat mengurangi persepsi nyeri dan membantu mengurangi ketegangan otot (Mander dalam Watiyah, 2013).

\section{KESIMPULAN DAN SARAN}

Secara klinis maupun statistic intervensi posisi menyusui biologic nurturing baby led feeding dapat menurunkan skala nyeri pada ibu post secsio caesaria. Posisi menyusui biologic nurturing baby led feeding dapat direkomendasikan sebagai terapi untuk membantu menurunkan nyeri khususnya pada ibu post secsio caesaria dan bagi tenaga kesehatan diharapkan memberikannya posisi ini sebagai bagian dari asuhan kebidanan untuk menurunkan nyeri post secsio caesaria.

\section{DAFTAR PUSTAKA}

Aminah, M.S. (2011). Seri Buku Pintar Baby's Corner Kamus Bayi 0-12 bulan. Jakarta : Luxima

Colson, S. (2012). Biological Nurturing: the laid-back breastfeeding revolution.

Colson, S.D., Meek J.H., and Hawdon, J.M. (2008). Optimal positions for the release of primitive neonatal reflexes stimulating breastfeeding. Early Human Development, 84, 441-449. http://linkinghub.elsevier.com/retrieve /pii/S0378378207002423.

Fraser dan Cooper. (2009). Myles Buku Ajar Bidan. $14^{\text {th }}$ ed. Jakarta: EGC.

Hidayat, A. (2007). Metode Penelitian Kebidanan dan Teknik Analisis Data. Jakarta : Salemba Medika.

Julianti, dkk. (2014). Materi Pelatihan Postnatal Care. Jakarta: Universitas Indonesia.

Kartikawati, Dewi. (2011). Dasar-Dasar Keperawatan Gawat Darurat. Jakarta: Salemba Medika. 
S Rini, I H Susanti | Penurunan Nyeri Pada lbu Post Sectio Caesaria Pasca Intervensi Biologic Nurturing Baby Led Feeding

Kementrian Kesehatan RI. (2013). Riset Kesehatan Dasar 2013. Diakses tanggal 27 Juni 2017 dari http://depkes.go.id/downloads/riskesd as2013/Hasil\%20Riskesdas\%202013 .pdf

Lisa, U.F., Jalina, M. and Marniati. (2017). Comparison of relaxation with counterpressure massage techniques for reduce pain first stage of labor. In AIP Conference Proceedings (Vol. 1885, No. 1, p. 020179). AIP Publishing.

Nursalam. (2015). Manajemen Keperawatan. Jakarta: Salemba Medika.

Potter, P.A. and Perry, A.G. ( 2010). Canadian fundamentals of nursing. Mosby/Elsevier.

Raymond S Sinatra, Osca A de Leon-Casasola, Brian Ginsberg, Eugene R Viscusi. (2009). Acute Pain Management. USA: Cambrige University Press.

Rini, S. and Kumala, F.D. (2016). Panduan Asuhan Nifas dan Efindence Based Practice. Yogyakarta: Deepublish.

Suryaningsih, Retno M. (2010). Skripsi: Hubungan Umur dan Paritas dalam Kejadian Perdarahan Postpartum di RSUD Panembahan Senopati Bantul. Poltekkes Kemenkes Yogyakarta.

Watiyah. (2013). Karya tulis ilmiah: Perbedaan Skala Nyeri Persalinan Kala I Sebelum Dan Sesudah Massage Counter Pressure Pada Ibu Bersalin Di Wilayah Kerja Puskesmas Pekuncen Kabupaten Banyumas. STIKES Harapan Bangsa Purwokerto.

Yuliatun, L. (2008). Penanganan Nyeri Persalinan Dengan Metode Nonfarmakologi. Malang : Bayumedia Publishing. 